\title{
PpEst is a novel PBAT degrading polyesterase identified by proteomic screening of Pseudomonas pseudoalcaligenes
}

\author{
Paal W. Wallace ${ }^{1,2,3}$ - Karolina Haernvall ${ }^{4}$ - Doris Ribitsch ${ }^{4,5}$ - Sabine Zitzenbacher ${ }^{2}$. \\ Matthias Schittmayer ${ }^{1,3}$ - Georg Steinkellner ${ }^{2}$ - Karl Gruber ${ }^{2,6}$ • Georg M. Guebitz ${ }^{4,5}$. \\ Ruth Birner-Gruenberger ${ }^{1,2,3}$
}

Received: 20 July 2016 /Revised: 27 October 2016 / Accepted: 5 November 2016 /Published online: 21 November 2016

(C) The Author(s) 2016. This article is published with open access at Springerlink.com

\begin{abstract}
A novel esterase, PpEst, that hydrolyses the coaromatic-aliphatic polyester poly(1,4-butylene adipate-co-terephthalate) (PBAT) was identified by proteomic screening of the Pseudomonas pseudoalcaligenes secretome. PpEst was induced by the presence of PBAT in the growth media and had predicted arylesterase (EC 3.1.1.2) activity. PpEst showed polyesterase activity on both whole and milled PBAT film releasing terephthalic acid and 4-(4-hydroxybutoxycarbonyl)benzoic acid while end product inhibition by 4-(4-hydroxybutoxycarbonyl)benzoic acid was observed. Modelling of an aromatic polyester mimicking oligomer into the PpEst active site indicated that the binding pocket could be big enough to accommodate large polymers. This is the first report of a PBAT degrading enzyme being identified by proteomic screening and shows that this approach can contribute to the discovery of new polymer hydrolysing enzymes.
\end{abstract}

Electronic supplementary material The online version of this article (doi:10.1007/s00253-016-7992-8) contains supplementary material, which is available to authorized users.

Ruth Birner-Gruenberger

ruth.birner-gruenberger@medunigraz.at

1 Research Unit for Functional Proteomics and Metabolic Pathways, Institute of Pathology, Medical University of Graz, Stiftingtalstrasse 24, 8010 Graz, Austria

2 Austrian Centre of Industrial Biotechnology, Petersgasse 14, 8010 Graz, Austria

3 Omics Center Graz, BioTechMed-Graz, Graz, Austria

4 Austrian Centre of Industrial Biotechnology, Konrad Lorenz Strasse 20, 3430 Tulln, Austria

5 Institute of Environmental Biotechnology, University of Natural Resources and Life Sciences, Konrad Lorenz Strasse 20, 3430 Tulln, Vienna, Austria

6 Institute of Molecular Biosciences, University of Graz, Humboldtstraße 50/III, 8010 Graz, Austria
Moreover, these results indicate that arylesterases could be an interesting enzyme class for identifications of polyesterases.

Keywords Proteomics $\cdot$ Poly (1,4-butylene adipate-co-terephthalate) (PBAT) $\cdot$ Secretome $\cdot$ Polymer degradation $\cdot$ Polyesterase $\cdot$ Arylesterase

\section{Introduction}

Biodegradable polyesters were introduced to the markets in the 1980s due to the increasing amounts of polyesters ending up as waste in garbage dumps and the fact that these very stable compounds hydrolyse very slowly. The advantage of this new group of polyesters over the traditional ones was that they were degradable by microorganisms at significant rates.

Poly(1,4-butylene adipate-co-terephthalate) (PBAT) was designed as a co-aliphatic-aromatic polyester that maintained some of the beneficial properties of aromatic polyesters while being easier to biodegrade due to its aliphatic components. Microbial biodegradation of PBAT (Kijchavengkul et al. 2010; Nakajima-Kambe et al. 2009; Trinh Tan et al. 2008; Witt et al. 2001) and other aromatic-aliphatic co-polyesters like poly(ethylene terephthalate)/poly(lactic acid) (Hu et al. 2008; Novotny et al. 2015) has been shown with organisms including species of Pseudomonas (Cerda-Cuellar et al. 2004; Novotny et al. 2015). However, few of the enzymes with the ability to hydrolyse these aromatic-aliphatic co-polyesters were identified or characterised. Furthermore, many of these studies only reported loss of polymer mass and did not investigate which ester bonds, aromatic or aliphatic, were actually cleaved.

The serine hydrolase TfH from Thermobifida fusca (Kleeberg et al. 2005; Muller et al. 2005), the lipase PfL1 from 
Pelosinus fermentans (Biundo et al. 2015), the esterases Cbotu EstA and Cbotu EstB from Clostridium botulinum (Perz et al. 2015) and the cutinases HiC from Humicola insolens, The Cut1 from Thermobifida cellulosilytica (Perz et al. 2016b) and Est1 and Est119 from Thermobifida alba (Thumarat et al. 2015; Thumarat et al. 2012) have all been reported to be able to hydrolyse PBAT. The producers of these enzymes are typical representatives of compost microbial populations or anaerobic environments (Clostridium). There is considerable less known about enzymes from typical aquatic microorganisms related to polyester degrading enzymes. Hence, Pseudomonas pseudoalcaligenes, as a typical aquatic microorganism, whose relatives have been reported to be involved in hydrolysis of other aromatic-aliphatic co-polymers (Novotny et al. 2015) and their building blocks (Cerda-Cuellar et al. 2004), was chosen for a proteomic-based screening towards polyesterases. All PBAT degrading enzymes previously investigated were identified either through functional screenings followed by chromatographic purification of the enzyme with subsequent peptide analysis for protein identification, or through in silico screening of publically available databases followed by cloning and expression in a host organism. However, the potential of proteomic screenings of the secretome of microorganisms to identify new PBAT degrading enzymes has not yet been exploited. There are several reasons why this approach would be able to contribute to the discovery of new polyester hydrolases.

Polyesters like PBAT are insoluble polymers that thus cannot be directly taken up by microorganisms. This means that for the polymer to be hydrolysed and potentially utilised, the polymer has to be hydrolysed outside the organism, which in turn leads to the presumption that the degradation is done by a secreted enzyme. By exploiting this idea, we could reduce the complexity of the sample to be analysed by restricting the search to a microorganism's secretome rather than its entire proteome.

Additionally, identification of an enzyme at the protein level rather than at the genomic level can remove problems related to non-functional genes that might arise due to incorrect gene-splicing recognition or different codon usage by different organisms (Behrens et al. 2011) which in turn could lead to non-functional enzymes. Also, proteomics has the major advantage that, like functional screening followed by protein isolation and identification, truly novel enzymes for a specific function can be identified even though their sequences, structures or regulation are very dissimilar to already reported proteins with the desired function (Sturmberger et al. 2015).

In this work, we demonstrate how a proteomic screening of the secretome of $P$. pseudoalcaligenes led to the identification of an esterase that is induced by the presence of PBAT and that, when recombinantly expressed, can hydrolyse the coaromatic-aliphatic polyester PBAT.

\section{Experimental procedures}

\section{Chemicals and materials}

The PBAT film and aromatic polyester mimicking oligomer bis(4-(benzoyloxybutyl)terephthalate (BABuTABuBA) were synthesised as previously described (Perz et al. 2016a) and kindly provided by BASF SE (Germany). BABuTABuBA was designed to contain bonds between aromatic and aliphatic moieties; the hydrolysis of which is known to be the limiting step in hydrolysis of polyesters (Perz et al. 2016b). The properties of the PBAT film were as follows: thickness of $50 \mu \mathrm{m}$, glass transition temperature $(\mathrm{Tg})$ of $-34{ }^{\circ} \mathrm{C}$, melting temperature of $125.3{ }^{\circ} \mathrm{C}$, molecular weight of $65,000 \mathrm{~g} / \mathrm{mol}, \mathrm{M}_{\mathrm{w}} / \mathrm{M}_{\mathrm{n}}$ of 3.4 and a crystallinity of $\sim 10 \%$ (Perz et al. 2016b). Poly(L-lactic acid) PLLA (PLA) film, thickness 0.05 mm (LS373275 M K S) (crystallinity of 60-70\%), and amorphous poly(ethylene terephthalate) (PET) film, thickness $0.25 \mathrm{~mm}$ (LS406760), were purchased from Goodfellow (UK). P. pseudoalcaligenes subsp. pseudoalcaligenes (DSM 50188) was obtained from LeibnizInstitute DSMZ-German Collection of Microorganisms and Cell Cultures in freeze-dried form. All solvents used were of HPLC grade. Unless stated otherwise, chemicals were purchased through Sigma-Aldrich.

\section{Induction of $P$. pseudoalcaligenes and collection of supernatant}

P. pseudoalcaligenes was cultured in suspension in media consisting of $5 \mathrm{~g} / \mathrm{L}$ soy bean peptone and $3 \mathrm{~g} / \mathrm{L}$ meat extract adjusted to $\mathrm{pH}$ 7.0. The culture was kept at $28^{\circ} \mathrm{C}$ with orbital shaking at $100 \mathrm{rpm}$ in the dark. For supplementation of media with polymer $0.5 \mathrm{~g}$ cellulose (in the form of toothpicks), $1 \mathrm{~g}$ milled PBAT or $100 \mathrm{mg}$ of the aromatic polyester mimicking oligomer BABuTABuBA was added to $50 \mathrm{~mL}$ of media. Organisms were cultured for either $9 \mathrm{~h}$ or 3 days before the supernatant was collected. Fifty-millilitre cultures were transferred to $50-\mathrm{mL}$ conical centrifugation tubes and centrifuged at $4{ }^{\circ} \mathrm{C}$ and $4000 \times g$ for $30 \mathrm{~min}$ in a swing-bucket rotor. Supernatant was collected and re-centrifuged as above to yield the final supernatant for analysis.

\section{Sample preparation of proteomic analysis}

Two-millilitre supernatant from each culture condition was centrifuged for $1 \mathrm{~h}$ at $10,000 \times g$ and $4{ }^{\circ} \mathrm{C}$. The supernatant was then transferred to an Amicon Ultra $10 \mathrm{kDa}$ cut-off spin filter (Merck, Germany) and spun at $4000 \times g$ for $1 \mathrm{~h}$ at $4{ }^{\circ} \mathrm{C}$ to remove soy bean and bovine peptides originating from the media. Then $4 \mathrm{~mL} 8 \mathrm{M}$ urea was added to the retentate and spun at $4000 \times g$ for $30 \mathrm{~min}$ at $4{ }^{\circ} \mathrm{C}$ to wash the protein suspension. Next, $4 \mathrm{~mL} 100 \mathrm{mM}$ ammonium bicarbonate was added to the retentate and spun at $4000 \mathrm{x} g$ for $1 \mathrm{~h}$ at $4{ }^{\circ} \mathrm{C}$. 
Finally, the retentate was transferred to a 1.5-mL Eppendorf tube and the proteins were precipitated with 6 volumes of acetone at $-20{ }^{\circ} \mathrm{C}$ overnight. Proteins were pelleted at $10,000 \times g$ and $4{ }^{\circ} \mathrm{C}$, solvent was removed and the pellet was washed once with $100 \mu \mathrm{L}$ cold acetone. Proteins were reduced and alkylated by dissolving the pellet in $20 \mu \mathrm{L}$ buffer containing $10 \mathrm{mM}$ tris(2-carboxyethyl)phosphine, $20 \mathrm{mM}$ iodoacetamide, $4 \mathrm{M}$ urea, $2 \%$ sodium dodecyl sulphate (SDS), $0.25 \mathrm{M} \mathrm{NaCl}$ and incubated for $1 \mathrm{~h}$ at $37{ }^{\circ} \mathrm{C}$ at $550 \mathrm{rpm}$ in the dark. Five microlitres NuPAGE LDS sample buffer $(4 \times)$ and $2 \mu \mathrm{L}$ NuPAGE sample reducing agent $(10 \times)$ were added to the sample prior to incubation for $5 \mathrm{~min}$ at $95{ }^{\circ} \mathrm{C}$. Sample was loaded on a 20 well NuPAGE $4-12 \%$ Bis Tris Midi gel (Invitrogen, USA) and run at a constant $9 \mathrm{~W} /$ gel to remove small contaminants. Gel was fixed with $10 \%$ ethanol, $7 \%$ acetic acid in water and stained with Coomassie Brilliant Blue G. The entire lanes were cut out and cut into seven pieces which were destained using repeated incubations in $25 \%$ acetonitrile at $37^{\circ} \mathrm{C}$ and $550 \mathrm{rpm}$. Proteins were digested in-gel by $1.5 \mu \mathrm{g}$ methylated trypsin (modified porcine trypsin, Promega, USA) in $120 \mu \mathrm{L} 50 \mathrm{mM}$ ammonium bicarbonate, $10 \mathrm{mM} \mathrm{CaCl}_{2}$ overnight at $37^{\circ} \mathrm{C}, 550 \mathrm{rpm}$. Peptides were extracted from the gel pieces and the extract was dried in a vacuum centrifuge. Dried peptides were redissolved in $20 \mu \mathrm{L} 0.1 \%$ formic acid just before analysis by HPLC-MS/MS.

\section{HPLC-MS/MS analysis}

Ten microlitres of the sample was injected and separated by nano-HPLC on an Ultimate 3000 system (Dionex) after enrichment on a PepMap100 C18, $5 \mu \mathrm{m}, 300 \mu \mathrm{m} \times 5 \mathrm{~mm}$ precolumn (Thermo Scientific, USA) on an Acclaim PepMap RSLC-C18, $2 \mu \mathrm{m}, 75 \mu \mathrm{m} \times 50 \mathrm{~cm}$ nanoviper nano-column (Thermo Scientific, USA) using the following gradient: solvent A: water, $0.1 \%$ formic acid; solvent B: acetonitrile, $0.1 \%$ formic acid; 0-5 min 5\% B; 5-90 min 5-30\% B, 9090.1 min 30-95\% B, 90.1-105 min 95\% B, 105-105.1 min 95-5\% B, 105.1-120 min re-equilibration at 5\% B. Flow rate was $250 \mathrm{~nL} / \mathrm{min}$. The separated peptides were directly analysed in an OrbiTrap Velos Pro (Thermo Scientific, USA) in positive ion mode by alternating full scan MS (m/z 300-2000, 60,000 resolution at $\mathrm{m} / \mathrm{z} 200$ ) and MS/MS by CID in the iontrap of the 20 most intense peaks with dynamic exclusion enabled.

\section{Data analysis}

The resulting spectra were analysed by searching a custom database. The database contained all protein entries for Pseudomonas in the NCBI database $(1,805,231$ entries downloaded on Jan. 25th, 2015), a publically available list of common contaminants (http://www.thegpm.org/crap/) and a custom protein entry (GI: 012345$)$ for dimethylated trypsin where all lysines were replaced with the custom amino acid $\mathrm{J}$ to avoid false positives resulting from autolysis of modified trypsin (Schittmayer et al. 2016). Searches were performed in Mascot 2.2 (Matrix Science, London, UK). The spectra from the seven gel pieces originating from a single supernatant were analysed together resulting in one protein list per supernatant. Detailed settings: Enzyme: trypsin (with the added specificity of J equal to K) (Schittmayer et al. 2016); max. missed cleavage sites: 2; N-terminus: hydrogen; C-terminus: free acid; carbamidomethylation on cysteine as fixed modification; oxidized methionine, acetylation of $\mathrm{N}$-terminus, demonomethylation of $\mathrm{J}$ and dedimethylation of $\mathrm{J}$ as variable modifications (Schittmayer et al. 2016); maximum precursor charge 3; precursor mass tolerance $+/-10 \mathrm{ppm}$; product mass tolerance $+/-0.7$ $\mathrm{Da}$; acceptance parameters were 1 or more identified distinct peptides after automatic validation; percolator active (decoy search, with a false discovery rate set below 5\%). The mass spectrometry proteomics data have been deposited to the ProteomeXchange Consortium (http://proteomecentral. proteomexchange.org) via the PRIDE partner repository (Vizcaino et al. 2013) with the dataset identifier PXD004014.

\section{General recombinant DNA techniques}

All DNA manipulations described in this work were performed by standard methods (Sambrook et al. 1989). Restriction of DNA was performed using endonucleases NdeI and HindIII (New England Biolabs, USA). Dephosphorylation with alkaline phosphatase (Roche, Germany) and ligation with T4 DNA-ligase (Fermentas, Germany) were done in accordance to the manufacturer's instructions. Plasmid DNA was isolated by Wizard® Plus SV Minipreps DNA Purification Systems (Promega, Germany) and plasmids and DNA fragments were purified with Promega DNA purification kits. Vector pET26b(+) (Novagen, Merck KGaA, Germany) was chosen for expression of the constructed fusion proteins carrying a C-terminal 6xHisTag in E. coli BL21-Gold(DE3) (Stratagene, USA).

\section{Expression and purification of PpEst}

The gene coding for an esterase from $P$. pseudoalcaligenes (Genbank accession number WP_003460012) was codon optimised for expression in E. coli and commercially synthesised without signal peptide (GeneArt@, Life Technologies, USA). The gene was cloned over the restriction sites NdeI and HindIII into pET26b(+) and transformed into E. coli BL21Gold(DE3). Freshly transformed E. coli BL21-Gold(DE3) cells were used to inoculate $50-\mathrm{mL}$ LB medium supplemented with $40 \mu \mathrm{g} / \mathrm{mL}$ kanamycin that was cultivated at $37{ }^{\circ} \mathrm{C}$ and $130 \mathrm{rpm}$ overnight. This culture was used to inoculate $400 \mathrm{~mL}$ of fresh medium to an $\mathrm{OD}_{600}=0.1$ and cultivated at $37^{\circ} \mathrm{C}$ and 
$150 \mathrm{rpm}$ until $\mathrm{OD}_{600}=0.6$. After cooling down to $25^{\circ} \mathrm{C}$, the expression was induced by addition of isopropyl- $\beta$-Dthiogalactopyranosid (IPTG) to a final concentration of $0.05 \mathrm{mM}$. After expression for $20 \mathrm{~h}$ at $25^{\circ} \mathrm{C}$ and $140 \mathrm{rpm}$, the cells were harvested by centrifugation $\left(20 \mathrm{~min}, 10^{\circ} \mathrm{C}\right.$, $3200 \times \mathrm{g}$ ). Pellets from $400-\mathrm{mL}$ culture were suspended in 30 -mL NiNTA lysis buffer $\left(20 \mathrm{mM} \mathrm{NaH} \mathrm{PO}_{4}, 500 \mathrm{mM}\right.$ $\mathrm{NaCl}, 10 \mathrm{mM}$ imidazole, $\mathrm{pH}$ 7.4) and sonicated with threetimes 30-s pulses under ice cooling (Vibra Cell, Sonics Materials, Meryin/Satigny, Swiss Confederation). Lysates were cleared by centrifugation $\left(60 \mathrm{~min}, 4{ }^{\circ} \mathrm{C}, 3200 \times \mathrm{g}\right)$. PpEst was purified by HisTrap FF (GE Healthcare, Germany). Buffer was exchanged for $100 \mathrm{mM}$ Tris- $\mathrm{HCl}$ $\mathrm{pH} 7.0$ and purified enzyme stored at $-70{ }^{\circ} \mathrm{C}$.

\section{DNA sequencing, alignments and deposition of sequence data}

DNA was sequenced as custom service by Agowa (Germany). DNA analysis was performed with Vector NTI Suite 10 (Invitrogen, USA). BLAST search was performed using the ExPASy (Gasteiger et al. 2003) proteomics server of the Swiss Institute of Bioinformatics, and sequences of related proteins were aligned using the Clustal W program (Swiss EMBnet node server). The nucleotide sequence of PpEst has been deposited in the GenBank database under accession number KX002004.1.

\section{Hydrolytic activity of non-stimulated and stimulated supernatants}

Two hundred microlitres of supernatant were added to $800 \mu \mathrm{L}$ of $0.1 \mathrm{mM}$ 4-nitrophenyl butyrate (4-NPB) solution $\mathrm{pH} 8.0$ in a $1-\mathrm{mL}$ half-micro cuvette and vortexed briefly before 4-NPB hydrolysis was measured continuously for $10 \mathrm{~min}$ by UVdetection of free 4-nitrophenolate at $405 \mathrm{~nm}$ on an Agilent Cary $100 \mathrm{UV}$-Vis spectrophotometer (USA). Autohydrolysis of 4-NPB was determined by adding $0.2-\mathrm{mL}$ freshly prepared medium instead of supernatant.

\section{Preferred carbon chain length of 4-nitrophenyl carboxylic acid ester substrates}

One-millilitre solutions of $0.1 \mathrm{mM}$ 4-nitrophenyl carboxylic esters (with carbon chain lengths from 2 to 14) in $150 \mathrm{mM}$ $\mathrm{NaCl}, 0.01 \%$ Triton $\mathrm{X}-100$ and $20 \mathrm{mM}$ Tris-HCl pH 8.0 were incubated with $1 \mu \mathrm{g}$ PpEst (in $3.75 \mu \mathrm{L} 100 \mathrm{mM}$ Tris- $\mathrm{HCl}$ $\mathrm{pH} 7.0$ ) at $30{ }^{\circ} \mathrm{C}$ for $30 \mathrm{~min}$ while the production of 4nitrophenolate was continuously measured at $405 \mathrm{~nm}$ on a Spectramax Omega (BMG-LABTECH, Germany). Autohydrolysis of 4-NPB was determined by the addition of $3.75 \mu \mathrm{L} 100 \mathrm{mM}$ Tris-HCl pH 7.0 without enzyme.

\section{Temperature optimum of enzymatic activity on 4-NPB}

Assay buffer of $150 \mathrm{mM} \mathrm{NaCl}, 0.01 \%$ Triton X-100 and $20 \mathrm{mM}$ Tris- $\mathrm{HCl} \mathrm{pH} 8.0$ was heated to temperatures between 25 and $90{ }^{\circ} \mathrm{C}$ in 5-degree increments. One microgram of PpEst in $7.5 \mu \mathrm{L} 100 \mathrm{mM}$ Tris-HCl was incubated with $1 \mathrm{~mL}$ of the buffer solution for $1 \mathrm{~min}$ before 4-NPB was added to a final concentration of $0.1 \mathrm{mM}$. Production of 4-nitrophenolate was measured continuously at $405 \mathrm{~nm}$ for $3 \mathrm{~min}$ on a Spectramax Plus (BMG-LABTECH, Germany). Autohydrolysis of 4-NPB was determined by the addition of $7.5 \mu \mathrm{L} 100 \mathrm{mM}$ Tris-HCl (pH 7.0) without enzyme.

\section{pH optimum of enzymatic activity}

PpEst was pre-incubated for $1 \mathrm{~h}$ in buffers ranging from $\mathrm{pH} 4$ to 11 (pH 4-6: $0.1 \mathrm{M}$ citric acid buffer, $\mathrm{pH}$ 7-9: $0.1 \mathrm{M}$ Tris$\mathrm{HCl}, \mathrm{pH}$ 10-11: $0.1 \mathrm{M}$ borate buffer). 4-NPB was added to the assay buffer $(150 \mathrm{mM} \mathrm{NaCl}, 0.01 \%$ Triton X-100, $20 \mathrm{mM}$ buffer with appropriate $\mathrm{pH}$ ) to a final concentration of $0.1 \mathrm{mM}$ and the reaction initiated by adding $1 \mu \mathrm{g}$ enzyme in $7.5 \mu \mathrm{L}$ to wells in a 96 well plate. Production of 4nitrophenolate and 4-nitrophenol was measured at $348 \mathrm{~nm}$ (their isosbestic point) (Biggs 1954) continuously for $10 \mathrm{~min}$ at $30^{\circ} \mathrm{C}$ on a Spectramax Plus (BMG-LABTECH, Germany). Autohydrolysis of 4-NPB was determined by addition of $7.5 \mu \mathrm{L}$ of the corresponding buffer without enzyme.

\section{Influence of $\mathrm{Ca}^{2+}$ concentration on PpEst activity and stability}

First, a $65 \mu \mathrm{M}$ PpEst solution in $100 \mathrm{mM}$ Tris-HCl pH 7.0 was incubated with $10 \mathrm{mM}$ ethylenediaminetetraacetic acid (EDTA) at $4{ }^{\circ} \mathrm{C}$ for $72 \mathrm{~h}$ to remove all bound $\mathrm{Ca}^{2+}$ and an aliquot was kept for subsequent activity measurement. Then, EDTA was removed from the protein solution by a succession of dilutions in $100 \mathrm{mM}$ Tris- $\mathrm{HCl} \mathrm{pH} 7.0$ and ultracentrifugation through an Amicon Ultra $3 \mathrm{kDa}$ cut-off spin filter (Merck, Germany) until EDTA concentration was calculated to be below $10 \mathrm{pM}$. Subsequently, $\mathrm{Ca}^{2+}$ was added to aliquots of the protein solution in ratios of $\mathrm{mol} \mathrm{Ca}^{2+}: \mathrm{mol}$ PpEst ranging from 0.05 to 20,000 , and the enzyme solutions were incubated for $3 \mathrm{~h}$ at $25^{\circ} \mathrm{C}$ prior to activity measurement.

For activity determination, $0.5 \mu \mathrm{g}$ of PpEst (after calcium removal and after readdition of different amounts of calcium) was added to $1 \mathrm{~mL} 0.1 \mathrm{mM}$ 4-NPB assay buffer $(150 \mathrm{mM}$ $\mathrm{NaCl}, 0.01 \%$ Triton $\mathrm{X}-100,20 \mathrm{mM}$ Tris- $\mathrm{HCl} \mathrm{pH} 8.0$ ) and production of 4-nitrophenolate was measured continuously at $405 \mathrm{~nm}$ for $3 \mathrm{~min}$ on a Spectramax Plus (BMGLABTECH, Germany). Autohydrolysis of 4-NPB was determined by the addition of $3.75 \mu \mathrm{L} 100 \mathrm{mM}$ Tris- $\mathrm{HCl} \mathrm{pH} 7.0$ without enzyme. To measure the effect of calcium on protein stability, $50 \mathrm{nM}, 10 \mathrm{mM}$ or $200 \mathrm{mM} \mathrm{Ca}^{2+}$ was added to 
solutions of $50 \mathrm{nM}$ PpEst in $100 \mathrm{mM}$ Tris-HCl pH 7.0 after all $\mathrm{Ca}^{2+}$ had been removed. The solutions were incubated at 50 , 65 or $80{ }^{\circ} \mathrm{C}$ for $72 \mathrm{~h}$. After $0,24,48$ and $72 \mathrm{~h}$, remaining 4NPB hydrolytic activity was measured as described above.

\section{$K_{\mathrm{m}}$ and $k_{\text {cat }}$ determination}

In a 96 well plate, $0.1 \mu \mathrm{g}$ of PpEst was incubated in $100-\mu \mathrm{L}$ assay buffer $(20 \mathrm{mM}$ Tris- $\mathrm{HCl} \mathrm{pH} 8.0,150 \mathrm{mM} \mathrm{NaCl}, 0.1 \%$ Triton- X100) at $25^{\circ} \mathrm{C}$ with 4-NPB concentrations ranging from $19 \mu \mathrm{M}$ to $80 \mathrm{mM}$, and the appearance of 4-nitrophenolate was measured continuously at $405 \mathrm{~nm}$ for $3 \mathrm{~min}$ on a Spectramax Plus (BMG-LABTECH, Germany). $K_{\mathrm{m}}$ and $k_{\text {cat }}$ were determined from functions derived using Sigmaplot 13.0 (Systat Software Inc., Germany) regression wizard equation 'Exponential Rise to maximum; Single, 2 Parameter'.

\section{Hydrolysis of polyesters}

Milled PBAT with particle sizes between 100 and $300 \mu \mathrm{m}$ and PBAT, PLA and PET films with the size of $10 \mathrm{~mm} \times 5 \mathrm{~mm}$ were used for the hydrolysis experiments of polymers. Prior to incubation, the films were washed with $5 \mathrm{~g} / \mathrm{L}$ Triton X-100, followed by $100 \mathrm{mM}$ sodium carbonate and subsequently $\mathrm{H}_{2} \mathrm{O}$. Each washing step was performed at $50{ }^{\circ} \mathrm{C}$ in a rotary shaker at $100 \mathrm{rpm}$ for $30 \mathrm{~min}$. To $5 \mu \mathrm{M}$ PpEst in $1 \mathrm{~mL}$ $100 \mathrm{mM}$ potassium phosphate buffer $\mathrm{pH} 7.0$ either $10 \mathrm{mg}$ BABuTABuBA, $10 \mathrm{mg}$ milled PBAT or $100 \mathrm{~mm}^{2}$ PBAT, PLA or PET film was added. Polymers were incubated in 2-mL Eppendorf tubes at 50,65 or $80{ }^{\circ} \mathrm{C}$ on a rotary shaker at $100 \mathrm{rpm}$ for $72 \mathrm{~h}$. Samples were taken after 0, 24 and $72 \mathrm{~h}$. Experiments were run in triplicates. In parallel, BABuTABuBA, milled PBAT and PBAT, PLA and PET films were incubated in buffer without enzyme to reveal any autohydrolysis.

Before the analysis of the release products of BABuTABuBA, PBAT and PET, the enzyme was precipitated by addition of icecold methanol (1:1 volume/volume) and the samples were acidified to $\mathrm{pH} 3.0$ with $\mathrm{HCl}$. The samples were centrifuged for $15 \mathrm{~min}$ at $0^{\circ} \mathrm{C}$ and $14,000 \mathrm{rpm}$ (Hermle Z300K, MIDSCI, Missouri, US) and the supernatant collected for further analysis.

Before the analysis of the release products of PLA, the enzyme was precipitated by a modified Carrez precipitation (Carrez 1908; Culhaoglu et al. 2011). Samples were acidified to $\mathrm{pH} 4.0$ with $\mathrm{HCl}, 20 \mu \mathrm{l}$ of Carrez reagent I was added and samples were mixed and incubated for $1 \mathrm{~min}$ at $25^{\circ} \mathrm{C}$. Then, $20 \mu \mathrm{l}$ Carrez reagent II was added to the mixture which was mixed and incubated for $5 \mathrm{~min}$ at $25^{\circ} \mathrm{C}$. The samples were centrifuged for $30 \mathrm{~min}$ at $25^{\circ} \mathrm{C}$ and $14,000 \mathrm{rpm}$ (Hermle Z300K, MIDSCI, Missouri, US). Finally, supernatants were filtered through $0.45-\mu \mathrm{m}$ nylon filters.

\section{Quantification of hydrolysis products}

The samples from PBAT and BABuTABuBA hydrolysis were analysed by HPLC-UV on a system consisting of a Dionex UltiMate 1813000 pump (Dionex Cooperation, USA), a Dionex ASI-100 automated sample injector, a Dionex UltiMate 3000 column compartment and a Dionex UVD $340 \mathrm{U}$ photodiode array detector. The hydrolysis products were separated by a reversed phase column (XTerra ${ }^{\circledR} \mathrm{RP} 18$, $3.5 \mu \mathrm{m}, 3.0 \mathrm{~mm} \times 150 \mathrm{~mm}$ ) with the recommended precolumn (Waters Corporation, USA) using a non-linear gradient: solvent $\mathrm{A}: \mathrm{H}_{2} \mathrm{O}$, solvent $\mathrm{B}$ : acetonitrile, solvent $\mathrm{C}: 0.1 \%$ formic acid; solvent $\mathrm{C}$ is at $20 \%$ constantly; $0-4.5 \mathrm{~min} 8 \% \mathrm{~B}$; 4.5-5 min 8-20\% B; 5-13 $\min 20-30 \%$ B; $13-17 \min 30$ $50 \% \mathrm{~B} ; 17-17.5 \min 50-80 \% \mathrm{~B} ; 17.5-18 \min 80 \% \mathrm{~B} ; 18$ $19 \min 80-8 \% \mathrm{~B} ; 19-25 \min 8 \% \mathrm{~B}$. All eluents were of HPLC grade. The injection volume was $5 \mu \mathrm{L}$ and the flow rate was $0.5 \mathrm{~mL} / \mathrm{min}$. The column compartment was kept at $25^{\circ} \mathrm{C}$. The expected release products terephthalic acid (TA), 4-(4hydroxybutoxycarbonyl)benzoic acid (BuTA) and benzoic acid (BA) were detected via UV spectroscopy at 241 and $228 \mathrm{~nm}$. The release products were qualified and quantified by external calibration curves. The reported values for release of products have had the values from the control samples with no enzyme subtracted. The values seen in the controls with no enzyme also showed that the acidification by $\mathrm{HCl}$ did not lead to hydrolysis of the polymers.

PLA samples were analysed as published (Pellis et al. 2015), while PET samples were analysed by a modified version of the published method (Herrero Acero et al. 2011) described in detail in the supplementary material.

\section{Inhibition of PpEst by BuTA}

One hundred nanograms of PpEst were incubated in $100 \mu \mathrm{L}$ $100 \mu \mathrm{M} 4-\mathrm{NPB}$ in assay buffer $(20 \mathrm{mM}$ Tris- $\mathrm{HCl} \mathrm{pH} \mathrm{8.0,}$ $150 \mathrm{mM} \mathrm{NaCl}, 0.1 \%$ Triton $-\mathrm{X} 100$ ) in a 96 well plate together with BuTA in concentrations ranging from 0 to $1 \mathrm{mM}$. Activity was determined by the appearance of 4nitrophenolate at $405 \mathrm{~nm}$ on a Spectramax Plus (BMGLABTECH, Germany) and is given as activity relative to rate when no BuTA was present. $\mathrm{K}_{\mathrm{I}}$ was determined from the function derived using the Sigmaplot 13.0 (Systat Software Inc., Germany) regression wizard equation 'Ligand binding; one site competition'.

\section{Sequence comparisons}

The amino acid sequence of PpEst was aligned to the sequences of the known PBAT hydrolysing enzymes TfH, Cbotu_EstA, Cbotu_EstB, HiC and The_Cut1 individually using blastp with the BLOSUM62 algorithm with default settings. Protein similarity is given as percentages. 


\section{Modelling of PpEst}

The model of PpEst was generated using the Phyre2 server (Kelley et al. 2015) applying the crystal structure of TesA from Pseudomonas aeruginosa (expressed in E.coli) (PDB code: 4jgg, resolution $1.9 \AA$ ) as a template as it has $70 \%$ sequence similarity to PpEst. The tetrahedral intermediate was built using the Phyre2 model and BABuTABuBA as substrate. For the energy minimization, YASARA structure (15.10.18) was used (Krieger et al. 2002). Methyl acetate modelled as oxyanion was placed into the active site to form the proposed tetrahedral intermediate by pointing the deprotonated oxygen to the oxyanion hole (main chain of Gly47 and ND2 of Asn76). The active site Ser in the model had to be rotated (the oxygen was positioned at the same location as in the template which was used for modelling). The histidine (His160) was treated as protonated (HIP). Hydrogens were added and the covalently bound intermediate was treated as charged $(-1)$. The model was cleaned and hydrogen bonding networks were optimised. The AMBER03 force field (Duan et al. 2003) was used to apply partial charges. This complex was energy minimised using YASARA structure applying the standard energy minimization protocol. The all-atom minimization root-mean-square deviation (RMSD) of the complex after energy minimization was $0.761 \AA$ compared to the Phyre2 model. Additional functional groups of the substrate were then added successively followed by energy minimization steps until the final complex was created.

\section{Results}

\section{Extracellular esterase activity of $P$. pseudoalcaligenes}

Activity of potential extracellular hydrolases of $P$. pseudoalcaligenes was measured using 4-nitrophenyl butyrate as substrate. Although activity was seen (data not shown), there was no induction of hydrolytic activity by milled PBAT when compared to a control without PBAT, and it was observed that the organism was also not able to use PBAT as its sole carbon source. However, addition of milled PBAT still led to a distinct profile of secreted proteins.

To identify the enzymes responsible for the hydrolytic activity, the supernatants were subjected to proteomic screening. Across the four cultures induced or not induced with different poly- and oligomers (cellulose, milled PBAT or BABuTABuBA), a total of 4081 ungrouped proteins were identified. Among these, 25 were predicted to have esterase, lipase, cutinase or depolymerase activity (excluding DNA or RNA depolymerases) (Table 1). These enzyme classes were chosen as they were previously reported to hydrolyse polymers. Several candidates from the list were considered for cloning and expression.
As the target enzyme should preferably be able to cleave PBAT, a desired ability was to hydrolyse ester bonds adjacent to aromatic rings as well as aliphatic esters. Thioesterases cleave ester bonds next to sulfurs and were thus excluded. Phosphodiesterases and phospholipases were likewise excluded due to high substrate specificity for phospho(di)esters. Two enzymes (GI: 610708963 and GI: 667953879) containing transmembrane segments were excluded as these segments might negatively affect stability in solution. Due to the incomplete genomic sequence of $P$. pseudoalcaligenes, not all proteins in the sample could be identified with the $P$. pseudoalcaligenes protein database. Thus, the protein sequences of closely related organisms (all Pseudomonas proteins in NCBI) were included as they were assumed to be closely related in sequence to $P$. pseudoalcaligenes proteins. This allowed experimental MS spectra to be assigned to these closely related proteins from other organisms instead of being potentially falsely assigned to unrelated $P$. pseudoalcaligenes proteins. However, these protein hits from other species were subsequently excluded from consideration for cloning and expression as the protein sequence of these enzymes might not be exactly the same in P. pseudoalcaligenes and thus not reflect the analysed protein. Of the remaining enzymes, an esterase (GI: 610711757) (from now on named PpEst) was chosen for cloning and expression due to being identified only in the supernatant induced by PBAT, containing a signal peptide for secretion, originating from the correct organism and having a $70 \%$ sequence similarity to TesA (GI: 530537561) from P. aeruginosa which is known to have arylesterase activity (Kovacic et al. 2013).

\section{Cloning and expression of PpEst}

The gene coding for the esterase PpEst from P. pseudoalcaligenes (202 AA) was codon optimised and cloned over restriction sites $\mathrm{Ndel} /$ HindIII into pET26b(+) for expression in E. coli BL21-Gold(DE3) without N-terminal secretion signal peptide. For rapid purification, the $6 \mathrm{xH}$ is Tag was C-terminally fused to the enzyme. Heterologous expression of PpEst at 25 and $28^{\circ} \mathrm{C}$ resulted in strong protein bands in the soluble fractions around $20 \mathrm{kDa}$ corresponding well to the calculated mass of $20.3 \mathrm{kDa}$ with higher expression of soluble PpEst at $25^{\circ} \mathrm{C}$ than at $28^{\circ} \mathrm{C}$ (Supplemental Fig. S1).

\section{Characterisation of PpEst}

After expression and purification of PpEst from E.coli BL21-Gold(DE3), its substrate specificity, $\mathrm{pH}$ optimum, temperature optimum and stability and the effects of calcium on activity and stability were determined. Among 4nitrophenol esters of increasing carbon chain length $(\mathrm{C} 2$ 
Table 1 List of esterases and lipases identified in one or more of the supernatants of cultures of $P$. pseudoalcaligenes grown with standard media or with the addition of cellulose, PBAT or BABuTABuBA

\begin{tabular}{|c|c|c|c|c|c|}
\hline GI accession\# & Protein name & $\begin{array}{l}\text { No polymer } \\
\text { added }\end{array}$ & Cellulose & BABuTABuBA & PBAT \\
\hline 667953335 & Glycerophosphodiester phosphodiesterase (Pseudomonas mendocina S5.2) & $\mathrm{X}$ & $\mathrm{X}$ & $\mathrm{X}$ & $\mathrm{X}$ \\
\hline 782988588 & ACP phosphodiesterase (Pseudomonas pseudoalcaligenes) & $\mathrm{X}$ & $\mathrm{X}$ & $\mathrm{X}$ & $\mathrm{X}$ \\
\hline 610712135 & Esterase (Pseudomonas pseudoalcaligenes AD6) & $\mathrm{X}$ & $\mathrm{X}$ & $\mathrm{X}$ & $\mathrm{X}$ \\
\hline 674101979 & Acyl-CoA thioesterase (Pseudomonas sp. 1-7) & & $\mathrm{X}$ & $\mathrm{X}$ & $\mathrm{X}$ \\
\hline 782988138 & Glycerophosphodiester phosphodiesterase (Pseudomonas pseudoalcaligenes) & $\mathrm{X}$ & $\mathrm{X}$ & $\mathrm{X}$ & $\mathrm{X}$ \\
\hline 667951325 & Glycerophosphodiester phosphodiesterase (Pseudomonas mendocina S5.2) & $\mathrm{X}$ & & $\mathrm{X}$ & $\mathrm{X}$ \\
\hline 782987573 & 4-hydroxybenzoyl-CoA thioesterase (Pseudomonas pseudoalcaligenes) & $\mathrm{X}$ & $\mathrm{X}$ & $\mathrm{X}$ & $\mathrm{X}$ \\
\hline 782987758 & Thioesterase (Pseudomonas pseudoalcaligenes) & $\mathrm{X}$ & $\mathrm{X}$ & $\mathrm{X}$ & $\mathrm{X}$ \\
\hline 610712849 & Phosphodiesterase (Pseudomonas pseudoalcaligenes AD6) & & & & $\mathrm{X}$ \\
\hline 782987757 & Thioesterase (Pseudomonas pseudoalcaligenes) & & $\mathrm{X}$ & & $\mathrm{X}$ \\
\hline 610706739 & Phosphodiesterase (Pseudomonas pseudoalcaligenes AD6) & & & & $\mathrm{X}$ \\
\hline 68345928 & Arylesterase (Pseudomonas protegens $\mathrm{Pf}-5)$ & & & & $\mathrm{X}$ \\
\hline 610711757 & Esterase (Pseudomonas pseudoalcaligenes AD6) & & & & $\mathbf{X}$ \\
\hline 641464984 & Thioesterase superfamily protein (Pseudomonas sp. P482) & $\mathrm{X}$ & $\mathrm{X}$ & $\mathrm{X}$ & \\
\hline 782986630 & Diguanylate phosphodiesterase (Pseudomonas pseudoalcaligenes) & $\mathrm{X}$ & $\mathrm{X}$ & $\mathrm{X}$ & \\
\hline 939992149 & $\begin{array}{l}\text { Glycerophosphoryl diester phosphodiesterase (Pseudomonas syringae pv. } \\
\text { alisalensis) }\end{array}$ & & & $\mathrm{X}$ & \\
\hline 564833263 & Phosphoesterase (Pseudomonas aeruginosa VRFPA07) & & & $\mathrm{X}$ & \\
\hline 610714766 & Carboxylesterase (Pseudomonas pseudoalcaligenes AD6) & & $\mathrm{X}$ & & \\
\hline 568075804 & Thioesterase (Pseudomonas sp. M1) & & $\mathrm{X}$ & & \\
\hline 610416967 & Chemotaxis-specific methylesterase (Pseudomonas aeruginosa PA96) & $\mathrm{X}$ & & & \\
\hline 739188356 & Acyl-CoA thioesterase (Pseudomonas oleovorans) & $\mathrm{X}$ & & & \\
\hline 610708936 & Esterase (Pseudomonas pseudoalcaligenes AD6) & $\mathrm{X}$ & & & \\
\hline 757245813 & Lysophospholipase L2 (Pseudomonas fluorescens) & $\mathrm{X}$ & & $\mathrm{X}$ & \\
\hline 667953879 & Lipase (Pseudomonas mendocina S5.2) & & $\mathrm{X}$ & & \\
\hline 801164442 & Lipase (Pseudomonas kilonensis) & & $\mathrm{X}$ & & \\
\hline
\end{tabular}

The esterase selected for cloning is depicted in bold. If the protein was identified under the given condition, it is indicated by $\mathrm{X}$

to $\mathrm{C} 14)$, the highest activity was seen towards 4nitrophenyl butyrate and hexanoate (Fig. 1a). The $\mathrm{pH}$ optimum for 4-NPB hydrolysis was found to be between 7 and 8 (Fig. 1b). $k_{\text {cat }}$ was determined to be $1.98 \mathrm{~s}^{-1}$, while $K_{\mathrm{m}}$ was $4.85 \mathrm{mM}$ for 4 -NPB. These values are in the lower and higher ranges, respectively, of values previously reported (Table 2), but, as previously reported, there is not necessarily a direct connection between an enzyme's ability to hydrolyse the soluble 4-NPB and its ability to hydrolyse insoluble polymers (Ribitsch et al. 2015). PpEst

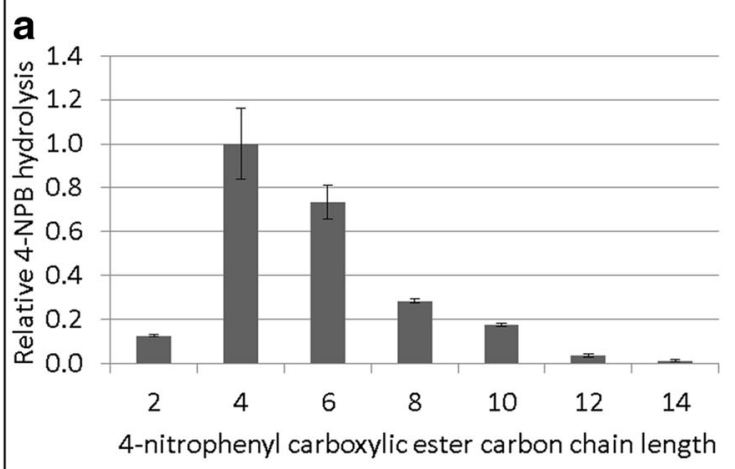

Fig. 1 Hydrolysis of 4-nitrophenyl esters and pH optimum. a PpEst substrate specificity towards 4-nitrophenyl carboxylic esters with increasing carbon chain lengths. b PpEst activity towards 4-NPB in

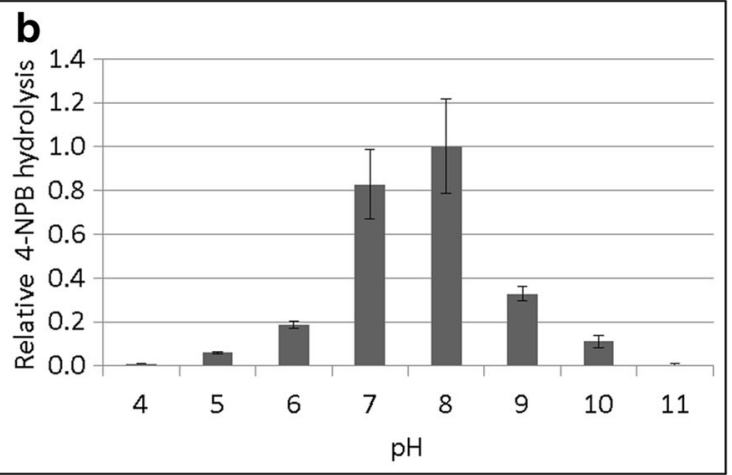

buffers ranging from $\mathrm{pH} 4$ to 11 . Values are means of triplicates and standard deviations are shown as bars 
Table 2 Comparison of some known PBAT degraders' $K_{\mathrm{m}}$ and $k_{\text {cat }}$ towards the soluble substrate 4-NPB

\begin{tabular}{llll}
\hline Enzyme & $k_{\text {cat }}\left(\mathrm{s}^{-1}\right)$ & $K_{\mathrm{m}}(\mathrm{mM})$ & Reference \\
\hline PpEst & 1.98 & 4.85 & \\
TfH & 220 & 0.62 & (Zhang et al. 2010) \\
Plf1 & 5 & 6.57 & (Biundo et al. 2015) \\
Cbotu_EstA & 71.86 & 1.95 & (Perz et al. 2015) \\
Cbotu_EstB & 5.84 & 1.30 & (Perz et al. 2015) \\
Thc_Cut1 & 325 & 0.8 & (Ribitsch et al. 2015) \\
\hline
\end{tabular}

activity towards 4-NPB was not significantly changed between 25 and $80{ }^{\circ} \mathrm{C}$ (Supplemental Fig. S2). As other serine hydrolases were found to be stabilised by $\mathrm{Ca}^{2+}$ (Bisogno et al. 2003; Diez et al. 1992; Ohto et al. 2005), this effect was also investigated for PpEst. Removing all $\mathrm{Ca}^{2+}$ ions by the addition of EDTA resulted in a complete loss of hydrolytic activity. When $\mathrm{Ca}^{2+}$ was reintroduced, PpEst activity returned and maximum activity was reached at $\sim 1.25 \mathrm{~mol} \mathrm{Ca}^{2+}$ per mol PpEst (Fig. 2). Increasing this ratio further did not increase the activity. To test PpEst stability at high temperatures and the effect of increased $\mathrm{Ca}^{2+}$ concentrations, $50 \mathrm{nM}$ PpEst solutions were incubated over 3 days at 50,65 or $80{ }^{\circ} \mathrm{C}$ with either $50 \mathrm{nM}, 10 \mathrm{mM}$ or $200 \mathrm{mM} \mathrm{Ca}^{2+}$. At $50{ }^{\circ} \mathrm{C}, 85 \%$ of enzyme activity remained after 3 days, while at $65{ }^{\circ} \mathrm{C}$ remaining activity was only $5 \%$ after 1 day and finally at $80{ }^{\circ} \mathrm{C}$ no activity remained after 1 day (Fig. 3). Increasing the $\mathrm{Ca}^{2+}$ above $50 \mathrm{nM}\left(\mathrm{mol} \mathrm{Ca}{ }^{2+}: \mathrm{mol}\right.$ PpEst $=1$ ) did not increase the stability of PpEst at any of the measured temperatures.

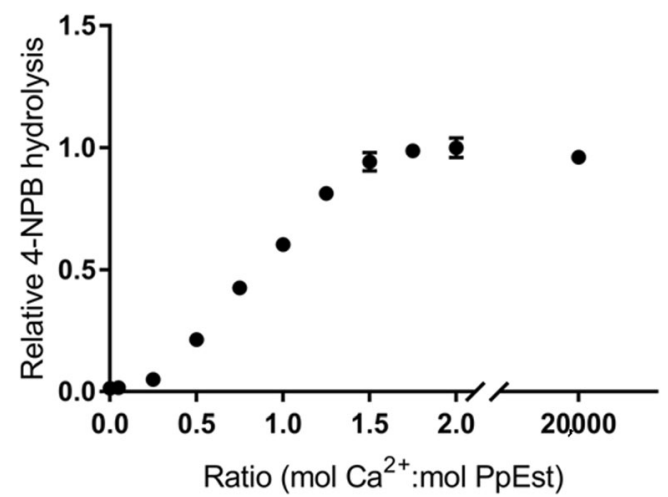

Fig. 2 PpEst activity with known $\mathrm{Ca}^{2+}$ concentrations. $\mathrm{Ca}^{2+}$ was removed from PpEst by complexation to EDTA. Then, EDTA was removed and known amounts of $\mathrm{Ca}^{2+}$ were added in ratios of mol $\mathrm{Ca}^{2+} /$ mol PpEst ranging from 0 to 20,000. Removal of $\mathrm{Ca}^{2+}$ completely, but reversibly, abolished PpEst's activity to hydrolyse 4-NPB. Activity was restored by reintroducing $\mathrm{Ca}^{2+}$ to the enzyme, reaching a maximum when the ratio of calcium/enzyme was $\sim 1.25$ and did not significantly change with higher calcium concentrations. Values are means of triplicates and standard deviations are shown as bars

\section{PpEst is a polyesterase that can hydrolyse PBAT and BABuTABuBA}

As PpEst was active on 4-NPB, its activity was tested on the aromatic polyester mimicking oligomer BABuTABuBA (Fig. 4a for structure) to determine if PpEst was able to cleave ester bonds next to aromatic rings. After $72 \mathrm{~h}$ at $50{ }^{\circ} \mathrm{C}$, PpEst had released 22 mol TA per mol PpEst (Fig. 4b) demonstrating its esterase activity on an aromatic compound.

Next, we investigated whether PpEst could degrade PBAT (Fig. 4c for structure). First milled PBAT film which is more easily accessible than whole film was tested due to its higher surface area and because milling of the film might have reduced the crystallinity. Hydrolysis of milled PBAT was observed at 50,65 and $80{ }^{\circ} \mathrm{C}$ with the highest activity seen at $65{ }^{\circ} \mathrm{C}$ (Fig. $4 \mathrm{~d}$ ).

Moreover, PpEst was also able to hydrolyse whole PBAT film at 50,65 and $80^{\circ} \mathrm{C}$, again with the highest activity seen at $65^{\circ} \mathrm{C}$ (Fig. 4e). The activity at $65^{\circ} \mathrm{C}$ was about 7 times higher on the milled film than on the whole film.

Even though only $5 \%$ of initial activity remained after $24 \mathrm{~h}$ at $65^{\circ} \mathrm{C}$ when the enzyme was incubated in a buffer alone, PpEst clearly had remaining activity after $24 \mathrm{~h}$ at $65{ }^{\circ} \mathrm{C}$ when the polymer was present. This could perhaps be explained by increased protein stability due to adsorbance to the polymer.

To test if PpEst is active also on other polyesters than PBAT, it was incubated with the aromatic polyester PET and the aliphatic polyester PLA. However, no hydrolysis of either polyester could be observed after 7 days of incubation (data not shown).

\section{PpEst is inhibited by the PBAT hydrolysis product BuTA}

The ability of PpEst to hydrolyse BuTA, one of the released degradation products, was tested, but no further hydrolysis could be observed (data not shown). Thus, we hypothesised that the enzyme might be inhibited by BuTA. Indeed, BuTA does inhibit PpEst almost completely (10\% activity remaining) at a concentration of $1 \mathrm{mM}$. $K_{\mathrm{I}}$ was determined to be $0.67 \mathrm{mM}$ (Supplemental Fig. S3).

\section{PpEst has low sequence similarity to known PBAT hydrolases}

To determine if PpEst was closely related to any known PBAT hydrolases, its sequence was compared to the amino acid sequence of six known enzymes with this function (Table 3). The sequence similarity is lower than $32 \%$ for all of them, indicating that PpEst is not closely related to any of the previously known PBAT hydrolases. 


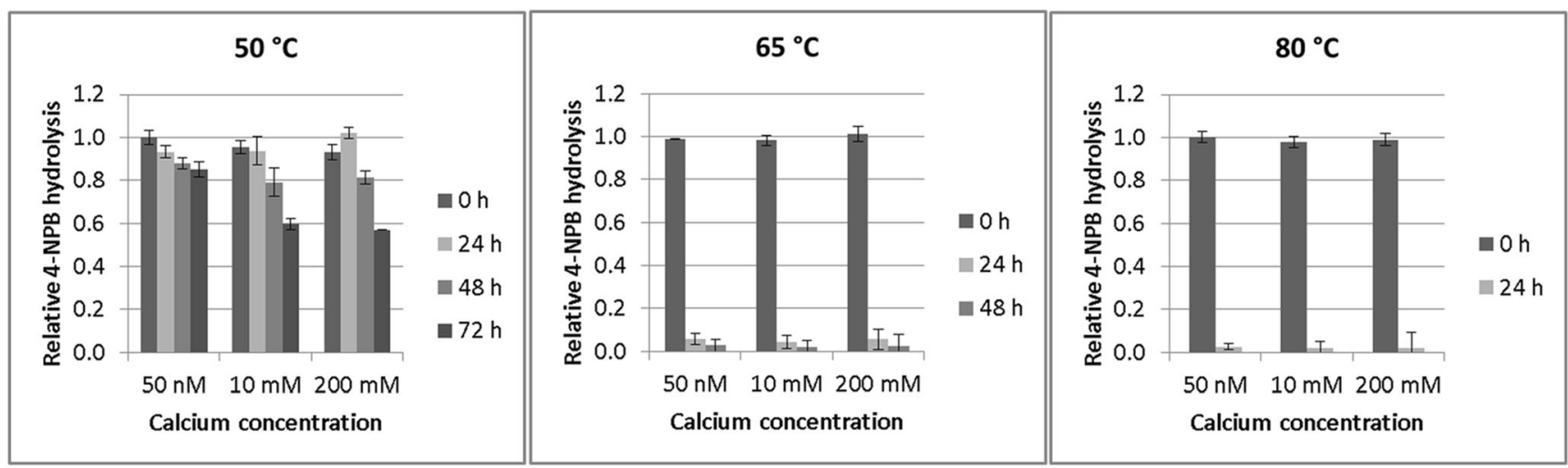

Fig. 3 PpEst stability at high temperatures and different $\mathrm{Ca}^{2+}$ concentration. PpEst was incubated for $72 \mathrm{~h}$ at either 50,65 or $80{ }^{\circ} \mathrm{C}$ with $\mathrm{Ca}^{2+}$ concentrations of $50 \mathrm{nM}, 10 \mathrm{mM}$ or $200 \mathrm{mM}$. Remaining 4NPB hydrolytic activity of PpEst was measured at $25^{\circ} \mathrm{C}$ every $24 \mathrm{~h}$ either until all activity was gone or $72 \mathrm{~h}$ had passed. When $\mathrm{Ca}^{2+}$ concentration

\section{PpEst structure modelled}

TesA (PDB code: $4 \mathrm{jGG}$ ) from $P$. aeruginosa has $70 \%$ sequence similarity to PpEst and is thus the enzyme with the highest similarity to PpEst in the RCSB Protein Data Bank. Due to this high similarity and the fact that its structure was determined by X-ray diffraction, it was used as a template to create a model of PpEst to predict the structure of the active site and the surrounding cavity. TesA was described to be a lysophospholipase and to have arylesterase activity (Kovacic et al. 2013) but was not reported to have polyesterase activity. For PBAT degrading enzymes, a sufficient size of the cavity is imperative as it allows access of insoluble polyesters to the active site of the enzyme. When modelling the substrate BABuTABuBA into the active site (Fig. 5a), we observed that the pocket was big enough to accommodate it if minor adjustments were made. The aromatic ring of the substrate did not quite fit into the proposed pocket without moving sidechains. Especially Leu79 and Ile159 were moved slightly during the energy minimization to fit the aromatic ring. This region may also open up a groove through the protein together with a loop (Gly149, Gly148) and a turn on the other side (Pro114, Pro113). This may extend the groove even further relaxing the somewhat restricted substrate geometry in the current model. The cavity surrounding the active site would then be relatively accessible for the solvent indicating that the enzyme could potentially allow large polymers to enter (Fig. 5b). PpEst was found to be dependent on $\mathrm{Ca}^{2+}$ to maintain its activity (Fig. 2). However, there is no $\mathrm{Ca}^{2+}$ binding domain in this model due to the fact that the template (TesA) does not contain a $\mathrm{Ca}^{2+}$ binding site.

\section{Discussion}

Identification of new enzymes for the degradation of polyesters was mainly achieved either by functional was $50 \mathrm{nM}, 85 \%$ of the initial activity remained after $72 \mathrm{~h}$ at $50^{\circ} \mathrm{C}$ while only $5 \%$ activity remained after $24 \mathrm{~h}$ at $65^{\circ} \mathrm{C}$ and was completely gone after $48 \mathrm{~h}$. At $80^{\circ} \mathrm{C}$, all hydrolytic activity was abolished after $24 \mathrm{~h}$. Higher $\mathrm{Ca}^{2+}$ concentrations did not increase PpEst stability. Values are means of triplicates and standard deviations are shown as bars

screenings followed by protein purification and peptide identification or by in silico searches of publically available genomic databases. Here we demonstrate that secretome screening of microorganisms is an efficient way to identify novel polyesterases from underinvestigated environments like aquatic ecosystems with $P$. pseudoalcaligenes being a typical representative.

We studied the extracellular proteome of $P$. pseudoalcaligenes and found that the supernatants of the cultured organism had hydrolytic ability when grown in standard media and when polymers were added to the media. From these supernatants, a total of 25 esterases and lipases were identified (Table 1). Only identified proteins predicted to be secreted enzymes were included for further investigation. Cytosolic proteins may have been identified after cell lysis over the incubation period of 3 days.

Among the identified esterases and lipases, PpEst was found to be induced by the presence of PBAT (as reported with other polyesterases, polymers and organisms (Alisch et al. 2004; Maeda et al. 2005; Wang et al. 2008)). PpEst was predicted to be a secreted enzyme and to have arylesterase activity based on sequence similarity to TesA. To our knowledge, arylesterases have not been reported to act as polyesterases, while, vice versa, several polyester degraders have been shown to be able to use aromatic as well as aliphatic polyesters as substrates. This is the first time, however, that an enzyme was investigated for its polyesterase activity due to its predicted arylesterase activity. We thus suggest that future searches for polyesterases should also include arylesterases in their scope as these enzymes may harbour the desired activities.

PpEst was successfully cloned and expressed in E.coli. Its hydrolytic abilities were characterised and the enzyme was modelled. One of the characteristics tested was the 
Fig. 4 Hydrolysis of BABuTABuBA and PBAT. a Structure of the aromatic polyester mimicking oligomer BABuTABuBA. b PpEst hydrolysis of BABuTABuTA into its components TA, BuTA and BA at $50{ }^{\circ} \mathrm{C}$ after 24 and $72 \mathrm{~h}$. c Structure of the aromatic-aliphatic co-polyester PBAT. d PpEst hydrolysis of milled PBAT film into its components TA and BuTA at 50,65 or $80^{\circ} \mathrm{C}$ after 24 and 72 h. e PpEst hydrolysis of whole PBAT film into its components TA and BuTA at 50,65 or $80^{\circ} \mathrm{C}$ after 24 and $72 \mathrm{~h}$. Values are means of triplicates and standard deviations are shown as bars

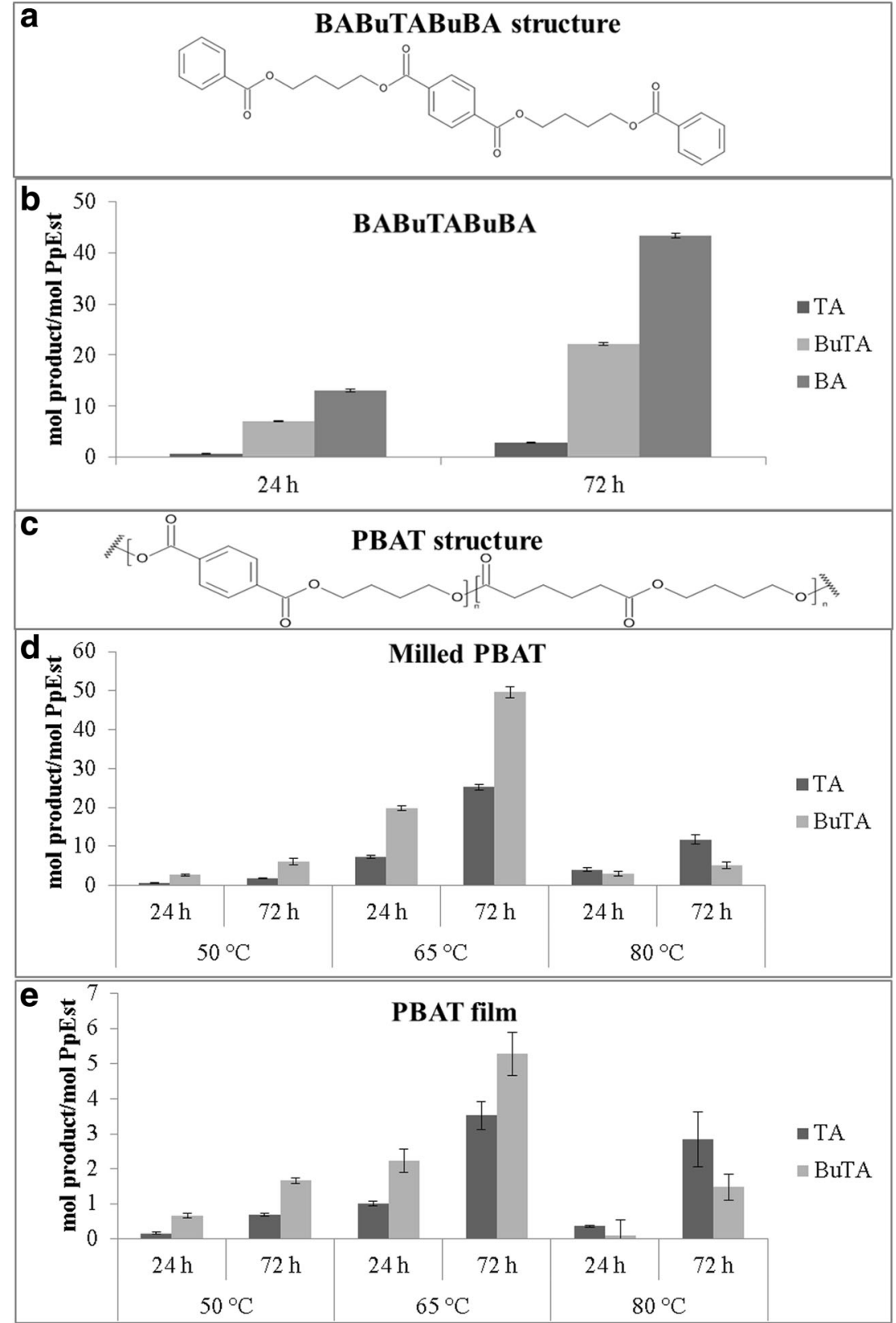

role of $\mathrm{Ca}^{2+}$ in PpEst activity and stability. $\mathrm{Ca}^{2+}$ was necessary for PpEst activity (Fig. 2) and it was observed that $\sim 1.25 \mathrm{~mol} \mathrm{Ca}^{2+}$ per mole enzyme was necessary for full activity. The influence of $\mathrm{Ca}^{2+}$ on PpEst stability at higher

Table 3 Sequence similarity of PpEst from P. pseudoalcaligenes aligned to PBAT hydrolysing enzymes

\begin{tabular}{ll}
\hline Enzyme & Similarity to PpEst (\%) \\
\hline TfH & 32 \\
Plf1 & 18 \\
Cbotu_EstA & 24 \\
Cbotu_EstB & 16 \\
HiC & 32 \\
Thc_Cut1 & 32 \\
\hline
\end{tabular}

temperatures was tested and increasing the $\mathrm{Ca}^{2+} / \mathrm{PpEst}$ ratio above 1.25 did not increase the stability of the enzyme at 50,65 or $80{ }^{\circ} \mathrm{C}$ (Fig. 3). It has to be noted, however, that our model lacks a binding site for this ion (Fig. 5) as the template structure of TesA does not contain a binding site. The model indicates that the active site pocket is relatively open and accessible to the solvent (Fig. 5b), which is imperative for the enzyme to be able to accommodate a polymer.

PpEst hydrolysed the aromatic polyester mimicking oligomer (BABuTABuBA) showing that it was capable of degrading aromatic polyester compounds (Fig. $4 \mathrm{~b}$ ). It was in turn also able to degrade milled PBAT film (Fig. 4d), a polyester substrate that is harder to access 


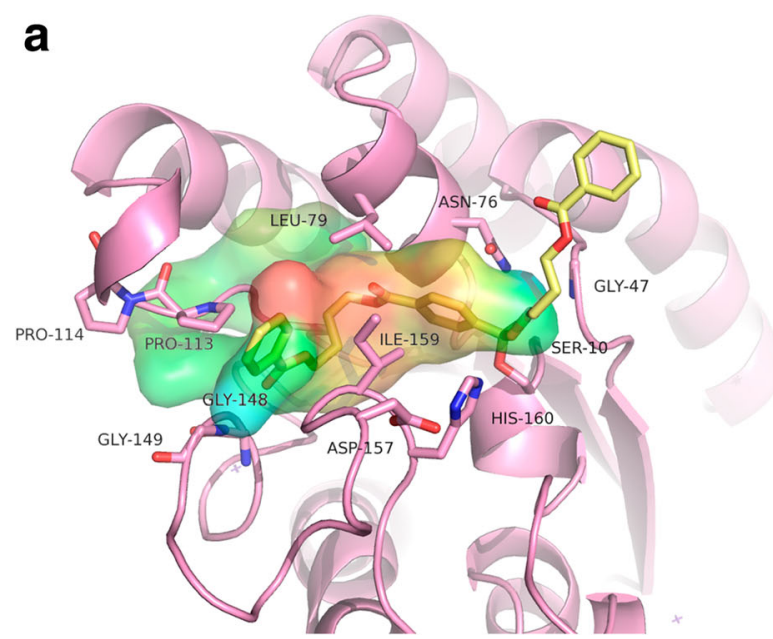

Fig. 5 Model of PpEst from $P$. pseudoalcaligenes complexed with BABuTABuBA. a Cavity of complex model of PpEst. Leu79, Ile156, Pro113 and Pro114 as well as the loop containing Gly149 and Gly148 may widen the groove on the active site. $\mathbf{b}$ PpEst model in complex with

due to its size, polymer chain lengths, hydrophobicity and insolubility. Finally, PpEst was tested on whole PBAT film and was able to hydrolyse the polyester even in this inaccessible form (Fig. 4e). This proof of polyester degrading activity demonstrates that proteomic screenings of an organism's extracellular proteome can lead to the identification of novel polyesterases.

Even though PpEst was able to degrade the aromaticaliphatic co-polyester PBAT, it was not able to degrade the commercially important aromatic polyester PET nor the aliphatic polyester PLA. PLA had a much higher crystallinity $(60-70 \%)$ than the PBAT film $(10 \%)$, which might explain why PpEst did not get access to the polymer chains and thus was unable to hydrolyse them. It is also possible that the active site of PpEst prefers substrates with an aromatic ring coupled to an aliphatic chain of the same length as in PBAT rather than to shorter aliphatic chains (PET), or purely aliphatic polyesters (PLA).

The stability of PpEst at higher temperatures was tested towards 4-NPB after incubation in buffer over $72 \mathrm{~h}$. Only $5 \%$ of the initial activity remained after $24 \mathrm{~h}$ at $65{ }^{\circ} \mathrm{C}$ (Fig. 3). However, when incubated with milled PBAT and PBAT film, PpEst displayed the highest hydrolytic activity at $65{ }^{\circ} \mathrm{C}$ (Fig. 4), and the increasing amount of release products after $24 \mathrm{~h}$ indicates that PpEst still remained highly active after this time point. This is in contrast to the data on enzyme stability over time in pure buffer. The increased stability in presence of polymers could be explained by adsorbance of PpEst to the polymer. Also, successful polymer hydrolysis is not only dependant on enzyme stability but also on e.g., the crystallinity, melting temperature and glass transition temperature of the polymer (Gan et al. 2004; Perz et al. 2016b). Therefore, it is important to find a compromise between

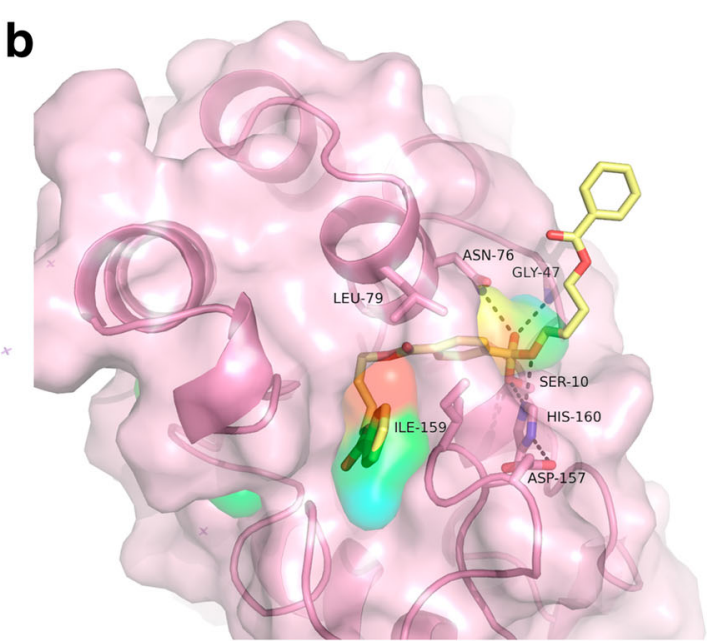

$\mathrm{BABuTABuBA}$ as a tetrahedral intermediate where the active site groove is shown as cavity surface. The predicted catalytic triad consists of Ser10, Asp157 and His160, while the oxyanion hole encompasses Gly47 and Asn 76

high incubation temperature and enzyme stability as low enzyme stability coupled with high polymer chain mobility (high temperature) might be more effective than high enzyme stability coupled with low polymer chain mobility (low temperature). The increased activity at $65{ }^{\circ} \mathrm{C} \mathrm{com}-$ pared to $50{ }^{\circ} \mathrm{C}$ could be due to the incubation temperature being closer to the melting temperature of the polymer, resulting in a higher polymer chain motility and thus increased accessibility to the polymeric chains for the enzyme. At $80{ }^{\circ} \mathrm{C}$ the hydrolytic activity is lower than at $65^{\circ} \mathrm{C}$ suggesting that PpEst is destabilised at this temperature and thus not able to take advantage of the increased polymer chain motility.

The ability of PpEst to degrade PBAT makes it a potential enzyme for use in e.g., waste management plants where polyesters need to be removed or in recycling schemes where the monomers of the polymers are to be recovered for reuse. However, it was observed that the degradation product BuTA (that results from enzymatic degradation of PBAT) inhibits PpEst. In our incubations of PpEst with PBAT films, we only reached concentrations of BuTA that could lead to $10 \%$ inhibition, but this could limit the potential PpEst has for PBAT degradation on a large scale. This could however be overcome by removing BuTA as soon as it is produced. One way to do this would be by a cascade reaction done by co-incubation with another enzyme that can hydrolyse this dimer as demonstrated in the case of Ideonella sakaiensis 201-F6 where PETase and MHETase collaborate to degrade PET, an aromatic polyester similar to PBAT (Yoshida et al. 2016). This kind of cascade could then also involve using organisms that use terephthalic acid as a carbon source (Zhang et al. 2013) turning this potentially toxic degradation product into biomass that can be reused. 
Acknowledgments Open access funding provided by Medical University of Graz (Graz, Austria). This work was supported by the Austrian Science Fund (FWF) doctoral school 'DK Metabolic and Cardiovascular Disease' (W1226) and project P26074, the Federal Ministry of Economy, Family and Youth (BMWFJ), the Federal Ministry of Traffic, Innovation and Technology (bmvit), the Styrian Business Promotion Agency SFG, the Standortagentur Tirol and ZITTechnology Agency of the City of Vienna through the COMETFunding Program managed by the Austrian Research Promotion Agency FFG.

\section{Compliance with ethical standards}

Ethical approval This article does not contain any studies with human participants or animals performed by any of the authors.

Conflict of interest The authors declare that they have no conflict of interest.

Open Access This article is distributed under the terms of the Creative Commons Attribution 4.0 International License (http:// creativecommons.org/licenses/by/4.0/), which permits unrestricted use, distribution, and reproduction in any medium, provided you give appropriate credit to the original author(s) and the source, provide a link to the Creative Commons license, and indicate if changes were made.

\section{References}

Alisch M, Feuerhack A, Muller H, Mensak B, Andreaus J, Zimmermann W (2004) Biocatalytic modification of polyethylene terephthalate fibres by esterases from actinomycete isolates. Biocatal Biotransfor 22(5-6):347-351. doi:10.1080/10242420400025877

Behrens GA, Hummel A, Padhi SK, Schatzle S, Bornscheuer UT (2011) Discovery and protein engineering of biocatalysts for organic synthesis. Adv Synth Catal 353(13):2191-2215. doi:10.1002/adsc.201100446

Biggs AI (1954) A spectrophotometric determination of the dissociation constants of p-nitrophenol and papaverine. Transactions of the Faraday Society (50):800-802

Bisogno T, Howell F, Williams G, Minassi A, Cascio MG, Ligresti A, Matias I, Schiano-Moriello A, Paul P, Williams EJ, Gangadharan U, Hobbs C, Di Marzo V, Doherty P (2003) Cloning of the first sn1DAG lipases points to the spatial and temporal regulation of endocannabinoid signaling in the brain. J Cell Biol 163(3):463468. doi:10.1083/jcb.200305129

Biundo A, Hromic A, Pavkov-Keller T, Gruber K, Quartinello F, Haernvall K, Perz V, Arrell MS, Zinn M, Ribitsch D, Guebitz GM (2015) Characterization of a poly(butylene adipate-co-terephthalate)-hydrolyzing lipase from Pelosinus fermentans. Appl Microbiol Biotechnol. doi:10.1007/s00253-015-7031-1

Carrez C (1908) Estimation of lactose in milk. Ann Chim Anal 13:17-22

Cerda-Cuellar M, Kint DPR, Munoz-Guerra S, Marques-Calvo MS (2004) Biodegradability of aromatic building blocks for poly(ethylene terephthalate) copolyesters. Polym Degrad Stab 85(2):865-871. doi:10.1016/j.polymdegradstab.2004.04.001

Culhaoglu T, Zheng D, Mechin V, Baumberger S (2011) Adaptation of the Carrez procedure for the purification of ferulic and p-coumaric acids released from lignocellulosic biomass prior to LC/MS analysis. J Chromatogr B Analyt Technol Biomed Life Sci 879(28):30173022. doi:10.1016/j.jchromb.2011.08.039

Diez E, Louis-Flamberg P, Hall RH, Mayer RJ (1992) Substrate specificities and properties of human phospholipases A2 in a mixed vesicle model. J Biol Chem 267(26):18342-18348
Duan Y, Wu C, Chowdhury S, Lee MC, Xiong GM, Zhang W, Yang R, Cieplak P, Luo R, Lee T, Caldwell J, Wang JM, Kollman P (2003) A point-charge force field for molecular mechanics simulations of proteins based on condensed-phase quantum mechanical calculations. J Comput Chem 24(16):1999-2012. doi:10.1002/jcc.10349

Gan ZH, Kuwabara K, Yamamoto M, Abe H, Doi Y (2004) Solid-state structures and thermal properties of aliphatic-aromatic poly(butylene adipate-co-butylene terephthalate) copolyesters. Polym Degrad Stab 83(2):289-300. doi:10.1016/S0141-3910(03)00274-X

Gasteiger E, Gattiker A, Hoogland C, Ivanyi I, Appel RD, Bairoch A (2003) ExPASy: the proteomics server for in-depth protein knowledge and analysis. Nucleic Acids Res 31(13):3784-3788. doi:10.1093/nar/gkg563

Herrero Acero E, Ribitsch D, Steinkellner G, Gruber K, Greimel K, Eiteljoerg I, Trotscha E, Wei R, Zimmermann W, Zinn M, Cavaco-Paulo A, Freddi G, Schwab H, Guebitz G (2011) Enzymatic surface hydrolysis of PET: effect of structural diversity on kinetic properties of cutinases from Thermobifida. Macromolecules 44(12):4632-4640. doi:10.1021/ma200949p

Hu XP, Osaki S, Hayashi M, Kaku M, Katuen S, Kobayashi H, Kawai F (2008) Degradation of a terephthalate-containing polyester by thermophilic Actinomycetes and Bacillus species derived from composts. J Polym Environ 16(2):103-108. doi:10.1007/s10924-008-0088-5

Kelley LA, Mezulis S, Yates CM, Wass MN, Sternberg MJE (2015) The Phyre2 web portal for protein modeling, prediction and analysis. Nat Protoc 10(6):845-858. doi:10.1038/nprot.2015.053

Kijchavengkul T, Auras R, Rubino M, Selke S, Ngouajio M, Fernandez RT (2010) Biodegradation and hydrolysis rate of aliphatic aromatic polyester. Polym Degrad Stab 95(12):2641-2647. doi:10.1016/j. polymdegradstab.2010.07.018

Kleeberg I, Welzel K, VandenHeuvel J, Muller RJ, Deckwer WD (2005) Characterization of a new extracellular hydrolase from Thermobifida fusca degrading aliphatic-aromatic copolyesters. Biomacromolecules 6(1):262-270. doi:10.1021/bm049582t

Kovacic F, Granzin J, Wilhelm S, Kojic-Prodic B, Batra-Safferling R, Jaeger KE (2013) Structural and functional characterisation of TesA - a novel lysophospholipase A from Pseudomonas aeruginosa. PloS one 8(7) doi:10.1371/journal.pone.0069125

Krieger E, Koraimann G, Vriend G (2002) Increasing the precision of comparative models with YASARA NOVA - a self-parameterizing force field. Proteins 47(3):393-402. doi:10.1002/prot.10104

Maeda H, Yamagata Y, Abe K, Hasegawa F, Machida M, Ishioka R, Gomi K, Nakajima T (2005) Purification and characterization of a biodegradable plastic-degrading enzyme from Aspergillus oryzae. Appl Microbiol Biotechnol 67(6):778-788. doi:10.1007/s00253-004-1853-6

Muller RJ, Schrader H, Profe J, Dresler K, Deckwer WD (2005) Enzymatic degradation of poly(ethylene terephthalate): rapid hydrolyse using a hydrolase from T-fusca. Macromol Rapid Comm 26(17):1400-1405. doi:10.1002/marc.200500410

Nakajima-Kambe T, Ichihashi F, Matsuzoe R, Kato S, Shintani N (2009) Degradation of aliphatic-aromatic copolyesters by bacteria that can degrade aliphatic polyesters. Polym Degrad Stab 94(11):19011905. doi:10.1016/j.polymdegradstab.2009.08.006

Novotny C, Erbanova P, Sezimova H, Malachova K, Rybkova Z, Malinova L, Prokopova I, Brozek J (2015) Biodegradation of aromatic-aliphatic copolyesters and polyesteramides by esterase activity-producing microorganisms. Int Biodeter Biodegr 97:2530. doi:10.1016/j.ibiod.201410.010

Ohto T, Uozumi N, Hirabayashi T, Shimizu T (2005) Identification of novel cytosolic phospholipase A(2)s, murine cPLA(2)\{delta $\}$, \{epsilon\}, and \{zeta\}, which form a gene cluster with $\operatorname{cPLA}(2)\{$ beta $\}$. J Biol Chem 280(26):24576-24583. doi:10.1074/jbc.M413711200

Pellis A, Acero EH, Weber H, Obersriebnig M, Breinbauer R, Srebotnik E, Guebitz GM (2015) Biocatalyzed approach for the surface functionalization of poly(L-lactic acid) films using hydrolytic enzymes. Biotechnol J 10(11):1739-1749. doi:10.1002/biot.201500074 
Perz V, Baumschlager A, Bleymaier K, Zitzenbacher S, Hromic A, Steinkellner G, Pairitsch A, Lyskowski A, Gruber K, Sinkel C, Kuper U, Ribitsch D, Guebitz GM (2015) Hydrolysis of synthetic polyesters by Clostridium botulinum esterases. Biotechnol Bioeng. doi:10.1002/bit.25874

Perz V, Bleymaier K, Sinkel C, Kueper U, Bonnekessel M, Ribitsch D, Guebitz GM (2016a) Data on synthesis of oligomeric and polymeric poly(butylene adipate-co-butylene terephthalate) model substrates for the investigation of enzymatic hydrolysis. Data in Brief 7:291298. doi:10.1016/j.dib.2016.02.029

Perz V, Bleymaier K, Sinkel C, Kueper U, Bonnekessel M, Ribitsch D, Guebitz GM (2016b) Substrate specificities of cutinases on aliphatic-aromatic polyesters and on their model substrates. New Biotechnol 33(2):295-304. doi:10.1016/j.nbt.2015.11.004

Ribitsch D, Acero EH, Przylucka A, Zitzenbacher S, Marold A, Gamerith C, Tscheliessnig R, Jungbauer A, Rennhofer H, Lichtenegger H, Amenitsch H, Bonazza K, Kubicek CP, Druzhinina IS, Guebitz GM (2015) Enhanced cutinase-catalyzed hydrolysis of polyethylene terephthalate by covalent fusion to hydrophobins. Appl Environ Microb 81(11):3586-3592. doi:10.1128/Aem.04111-14

Sambrook J, Fritsch EF, Maniatis T (1989) Molecular cloning: a laboratory manual, 2nd edn. Cold Spring Harbor Laboratory Press, Cold Spring Harbor

Schittmayer M, Fritz K, Liesinger L, Griss J, Birner-Gruenberger R (2016) Cleaning out the litterbox of proteomic scientists' favorite pet: optimized data analysis avoiding trypsin artifacts. J Proteome Res. doi:10.1021/acs.jproteome.5b01105

Sturmberger L, Wallace PW, Glieder A, Birner-Gruenberger R (2015) Synergism of proteomics and mRNA sequencing for enzyme discovery. J Biotechnol. doi:10.1016/j.jbiotec.2015.12.015

Thumarat U, Kawabata T, Nakajima M, Nakajima H, Sugiyama A, Yazaki K, Tada T, Waku T, Tanaka N, Kawai F (2015) Comparison of genetic structures and biochemical properties of tandem cutinase-type polyesterases from Thermobifida alba AHK119. J Biosci Bioeng 120(5):491-497. doi:10.1016/j.jbiosc.2015.03.006

Thumarat U, Nakamura R, Kawabata T, Suzuki H, Kawai F (2012) Biochemical and genetic analysis of a cutinase-type polyesterase from a thermophilic Thermobifida alba AHK119. Appl Microbiol Biot 95(2):419-430. doi:10.1007/s00253-011-3781-6

Trinh Tan F, Cooper DG, Marić M, Nicell JA (2008) Biodegradation of a synthetic co-polyester by aerobic mesophilic microorganisms. Polym Degrad Stab 93(8):1479-1485. doi:10.1016/j. polymdegradstab.2008.05.005

Vizcaino JA, Cote RG, Csordas A, Dianes JA, Fabregat A, Foster JM, Griss J, Alpi E, Birim M, Contell J, O'Kelly G, Schoenegger A, Ovelleiro D, Perez-Riverol Y, Reisinger F, Rios D, Wang R, Hermjakob H (2013) The proteomics identifications (PRIDE) database and associated tools: status in 2013. Nucleic Acids Res 41(D1):D1063-D1069. doi:10.1093/ nar/gks 1262

Wang X, Lu D, Jönsson LJ, Hong F (2008) Preparation of a PEThydrolyzing lipase from Aspergillus oryzae by the addition of bis(2-hydroxyethyl) terephthalate to the culture medium and enzymatic modification of PET fabrics. Engineering in Life Sciences 8(3):268-276. doi:10.1002/elsc.200700058

Witt U, Einig T, Yamamoto M, Kleeberg I, Deckwer WD, Muller RJ (2001) Biodegradation of aliphatic-aromatic copolyesters: evaluation of the final biodegradability and ecotoxicological impact of degradation intermediates. Chemosphere 44(2):289-299. doi:10.1016/S0045-6535(00)00162-4

Yoshida S, Hiraga K, Takehana T, Taniguchi I, Yamaji H, Maeda Y, Toyohara K, Miyamoto K, Kimura Y, Oda K (2016) A bacterium that degrades and assimilates poly(ethylene terephthalate). Science 351(6278):1196-1199. doi:10.1126/ science.aad6359

Zhang Y, Chen S, Xu M, Cavaco-Paulo A, Wu J, Chen J (2010) Characterization of Thermobifida fusca cutinase-carbohydratebinding module fusion proteins and their potential application in bioscouring. Appl Environ Microbiol 76(20):6870-6876. doi:10.1128/AEM.00896-10

Zhang YM, Sun YQ, Wang ZJ, Zhang J (2013) Degradation of terephthalic acid by a newly isolated strain of Arthrobacter sp.0574. S Afr J Sci 109(7-8) doi:Artn001910.1590/Sajs.2013/20120019 